\title{
Nationality, Ethnicity and the Well-Being Process in Occupational Samples
}

\author{
Omolaso Omosehin, Andrew P. Smith \\ Centre for Occupational and Health Psychology, School of Psychology, Cardiff University, Cardiff, United Kingdom \\ Email: omosehino@cardiff.ac.uk
}

How to cite this paper: Omosehin, O. and Smith, A.P. (2019) Nationality, Ethnicity and the Well-Being Process in Occupational Samples. Open Journal of Social Sciences, 7, 133-142.

https://doi.org/10.4236/jss.2019.75011

Received: May 4, 2019

Accepted: May 14, 2019

Published: May 17, 2019

\begin{abstract}
Well-being has been defined as optimal functioning and experience. In order to get a balanced picture of an individual's well-being, approaches that integrate both its positive and negative aspects have been suggested. One framework that allows for this integrated approach to well-being is the Demands-Resources Individual Effects (DRIVE) model. The current study was a cross-cultural study of 316 adults in paid employment from three distinct cultural backgrounds: White British, Ethnic Minorities (in the United Kingdom) and Nigerian. The aims of the study were to confirm the established effects of the DRIVE model and to investigate if cultural/ethnic background accounted for any differences in well-being across the three groups. The findings show that the established effects were observed in all groups. This suggests that cultural/ethnic background does not have much effect on well-being outcomes when controlling for established psychosocial predictors such as personality, job characteristics, social support and negative coping. These results support an objective well-being process rather than subjective well-being, which may be defined by a person's culture.
\end{abstract}

\section{Keywords}

Cross-Cultural Psychology, Cultural/Ethnic Differences, DRIVE Model, Cross-National Comparison

\section{Introduction}

Well-being is defined as "optimal psychological function and experience" [1]. It is a broad concept that can be categorized into negative and positive aspects and there is a tendency for much of well-being research to focus only on one aspect at the expense of the other. This is based on the assumption that the positive (e.g. happiness, positive affect etc.) and negative (e.g. anxiety, stress, depression 
etc.) aspects of well-being are opposites-therefore well-being can be inferred by the presence of positive well-being indicators and the absence of negative well-being indicators and/or vice-versa. This approach has been criticized as positive and negative well-being are not necessarily opposite ends on the same spectrum [1] [2] [3] [4]. Therefore, it has been suggested that well-being be considered a multi-dimensional process comprising both positive and negative aspects which need to be measured in an integrated manner.

One framework that allows for this integrated approach to measuring well-being is the Demands-Resources Individual Effects (DRIVE) model. The DRIVE model was developed by Mark and Smith [5], and it takes into account the synergistic effects of occupational and individual factors that can influence both positive and negative outcomes. As such the model seems fitting to measure well-being holistically. Added to that is the fact that the model was not intended as "a predictive model but rather a theoretical framework into which any relevant variables can be introduced" [5]. This makes it suitable and adaptable to various occupational settings and has thus been used to investigate well-being across various occupational and educational settings [6] [7] [8] [9] [10] etc.

However, because well-being is a multi-faceted construct and the DRIVE model is a "flexible" framework that can allow for the addition of various well-being variables, new problems arise. The advantage of being able to measure as many aspects of well-being as possible, though applaudable, has its own drawbacks. Typically, each well-being variable is measured with constructs consisting of their own battery of questions. The implication of this is that the more constructs are included in the measuring instruments, the bulkier the questionnaires become and the bulkier the questionnaires get, the less likely they are to be completed due to time demand [11] [12].

A possible solution to this problem is the use of single-item questions to measure each variable. This approach will provide the opportunity to measure as many variables as possible in a single study with a questionnaire while encouraging participation and discouraging attrition. Although single-item questions may provide a more practical alternative to multiple-item constructs, the academic community seem very skeptical to use them. Their major argument is that data from multiple-item scales are more likely to be reliable compared to single-items [13]. This argument has been largely refuted as some research has revealed that single-items can demonstrate satisfactory reliability [13] [14].

With the evidence in the support of single-items, Williams [15] developed the Well-being Process Questionnaire (WPQ) from the DRIVE model. It was designed to solve the problem of having to complete lengthy questionnaires measuring well-being. Thus, saving time and encouraging participation [11]. Many of the single-items in the WPQ have shown high validity and strong correlations with multiple-item scales [11] [12] [16]. Following the success of the WPQ in using single-items to predict well-being outcomes, the Smith Well-Being Questionnaire (SWELL) [17] was designed. 
The SWELL comprised 26 single-item questions from the WPQ and required even shorter time to complete-some studies reporting as little as 15 minutes [18]. The major advantage of the SWELL is that it contains more outcome measures and job characteristics than the WPQ. This should be expected as it was "designed to provide a detailed profile of the well-being of an organization" [19]. Both the WPQ and the SWELL were developed from the DRIVE model with the aim of using single-items to measure well-being and have been largely successful.

As the DRIVE model has been used in previous research, there are effects that are often replicated whenever it is used. Due to their reliability, these effects have come to be known as the "established effects". For instance, several studies [3] [9] [12] [20] [21] showed positive personality (high self-efficacy, self-esteem and optimism) to be a significant predictor of positive outcomes. Likewise, studies [9] [20] [21] replicated the finding that negative work characteristics and negative coping were predictors of negative outcomes. In line with these findings, the current study aimed to confirm if the established effects of the DRIVE model held true despite differences in nationality/ethnicity.

Capasso, Zurlo and Smith [22], using the DRIVE model, investigated the relationship between work characteristics and occupational health across different ethnic groups living and working in Italy. They found that ethnicity and job type had strong influences on the respondents' perceptions of their psychological and physical health. Although this study only focused on negative outcomes, it shows that differences in nationality potentially play a role in the well-being process. Similar findings were reported in a cross-national comparative study of Italian and Dutch nurses where nationality was found to significantly predict some of the positive and negative outcomes [23].

However, cross-national/cross-cultural comparisons raise the question of the adequacy of the model and/or measuring instrument as concerns have been raised about the validity of some instruments developed in one part of the world and used in another, not necessarily accounting for the cultural contexts [24]. To this end, the second aim of this study was to investigate if the DRIVE model was able to predict well-being across various cultural contexts. In particular, this study sought to find out if nationality/cultural/ethnic background had any significant impact on people's well-being.

\section{Methodology}

\subsection{Sample Description}

The sample comprised 316 working class adults, aged $18-66$ (mean $=37.45 ;$ SD $=11.05$ ) from three distinct cultural backgrounds: White British (living and working in the United Kingdom, UK), 105; Ethnic Minorities (living and working in the UK), 110 and Nigerian (living and working in Nigeria), 101. The respondents were from different occupations and the sample was almost evenly split across both genders, with females forming the slight majority (51.6\%). 67.4\% 
of the sample were married or cohabiting while the rest were single, divorced or widowed.

\subsection{Instrument}

Data were collected in three phases by the completion of a questionnaire via the Qualtrics online platform. The questionnaire was delivered in the English language in all three phases. As the questionnaire was basically the same, the data from the three phases were subsequently merged using the SPSS software. The instrument used comprised questions from the WPQ [15] and the SWELL [17]. A total of 41 questions were drawn from these instruments. The independent variables also referred to as the "established predictors" were negative work characteristics, positive work characteristics, positive personality, positive coping and negative coping. The scores for each of these predictors was derived by summing up the scores from all the individual questions representing that variable. For instance, the score for negative work characteristics was a sum of the scores from each individual question on negative work characteristics. Each question was answered by ascribing a score from $1-10(1=$ low, $10=$ high $)$ to a statement or question. The WPQ adopted this format based on statistical preference for visual scales over Likert scales for single items intended to represent entire constructs [9]. Furthermore, as the validity of a single-item is based on how well the respondent comprehends the question (especially in relation to the construct measured), the questions were presented in form of an initial statement or question followed by examples or explanations in brackets [9]. An example is presented with one of the questions for positive work characteristics: " $I$ feel that I get adequate control over my work (for example: I have a choice in what I do or how I do things, I am able to learn new things, I amable to be creative)".

The positive and negative outcomes were derived in the manner described for the predictors above. The question on depression, which was a component of the negative outcomes score is presented: "On a scale of one to ten, how depressed would you say you are in general (e.g. feeling 'down', no longer looking forward to things or enjoying things you used to)".

\subsection{Statistical Analyses}

The first step was to dichotomise the established predictors-negative work characteristics, positive work characteristics, positive personality, positive coping, negative coping-by splitting them into "high" and "low" groups at the median. Analysis of Variance (ANOVA) tests were subsequently performed for the prediction of positive and negative outcomes by the established predictors and nationality. Main effects of each of the established predictors and nationality, as well as, two-way interactions between each of the established predictors and nationality were done. Similar analyses were conducted with demographic variables. These analyses were performed using the SPSS software. 


\section{Results}

\subsection{Negative Outcomes}

ANOVAs were carried out to investigate the prediction of negative outcomes by the established predictors and nationality. Analyses were performed to determine if the established factors predicted negative outcomes singly (i.e. main effects) and in tandem with nationality (two-way interactions) while demographics (age and marital status) were controlled for. Age was also split at the median and interactions between nationality and demographics were explored in the prediction of negative outcomes. The main effect of nationality in the prediction of negative outcomes was also investigated Table 1 shows that nationality was not a significant predictor of negative outcomes.

Established effects were observed: negative work characteristics, negative coping (both $\mathrm{p}<0.001)$ and positive personality $(\mathrm{p}<0.05)$ all significantly predicted negative outcomes (see Table 2 for details). No significant effects were demonstrated by the other established predictors (results not presented). Age was found to predict negative outcomes (see Table 2) while marital status did not (not presented).

Although nationality, on its own, did not predict negative outcomes, significant effects were observed when it was combined with positive work characteristics $(\mathrm{F}(2,292)=5.1, \mathrm{p}<0.05)$; see Table 3 for the means of the interaction across the three nationalities/ethnicities). No other significant effects were observed when nationality was combined with the other established predictors or the demographic variables (not presented).

\subsection{Positive Outcomes}

The analysis mirrored those performed for the prediction of negative outcomes. The results of the analysis reveal that nationality was not a significant predictor of positive outcomes (see Table 1.). The established effects were also observed: negative work characteristics $(\mathrm{p}<0.05)$, positive work characteristics $(\mathrm{p}<0.001)$, positive personality $(\mathrm{p}<0.001)$ and positive coping all significantly predicted positive outcomes $(\mathrm{p}<0.05)$. Age was also found to be a significant predictor of positive outcomes (see Table 2), marital status was not a significant predictor of positive outcomes (result not presented).

When nationality was placed in tandem with each of the established predictors and demographic variables no significant effects were observed.

\section{Discussion}

The results show that the established effects were mostly retained, replicating findings from previous research using the DRIVE framework. These findings further support the argument for established effects in the prediction of well-being. Additionally, nationality was found not to predict either outcome. Putting these together could be pointing to well-being as an objective process that transcends national/cultural/ethnic boundaries rather than a subjective one. 
Table 1. Prediction of the outcomes by nationality.

\begin{tabular}{ccccc}
\hline \multirow{2}{*}{ Outcomes } & White British & Ethnic Minority & Nigerian & Sig. \\
\cline { 2 - 5 } & Mean (SD) & Mean (SD) & Mean (SD) & $\mathrm{F}(\mathrm{df})=$ F-value, $\mathrm{p}$ \\
\hline $\begin{array}{c}\text { Nationality } \\
\text { (Negative outcomes) }\end{array}$ & $37.3(1.2)$ & $35.7(1.0)$ & $37.8(1.5)$ & $\begin{array}{c}\mathrm{F}(2,292)=0.908, \\
\mathrm{p}=0.404\end{array}$ \\
$\begin{array}{c}\text { Nationality } \\
\text { (Positive outcomes) }\end{array}$ & $37.5(0.7)$ & $36.0(0.6)$ & $36.1(0.9)$ & $\begin{array}{c}\mathrm{F}(2,295)=1.577, \\
\mathrm{p}=0.208\end{array}$ \\
\hline
\end{tabular}

Table 2. Prediction of the outcomes by the established predictors and demographics.

\begin{tabular}{cccc}
\hline Outcomes & Mean (SD) & Mean $(\mathrm{SD})$ & $\begin{array}{c}\text { Sig. } \\
\mathrm{F}(\mathrm{df})=\mathrm{F} \text {-value, } \mathrm{p}\end{array}$ \\
\hline Age & $18-35$ & $>35$ & \\
Negative outcomes & $38.5(0.91)$ & $35.4(0.98)$ & $\mathrm{F}(1,292)=6.2, \mathrm{p}=0.013$ \\
Positive outcomes & $35.9(0.53)$ & $37.3(0.57)$ & $\mathrm{F}(1,292)=4.1, \mathrm{p}=0.043$ \\
Negative Work & Low & High & \\
Characteristics & $31.1(0.95)$ & $42.8(1.07)$ & $\mathrm{F}(1,292)=67.99, \mathrm{p}=0.000$ \\
Negative outcomes & $37.8(0.55)$ & $35.4(0.63)$ & $\mathrm{F}(1,292)=8.4, \mathrm{p}=0.004$ \\
Positive outcomes & Low & High & \\
Positive Personality & $39.4(1.06)$ & $34.6(0.99)$ & $\mathrm{F}(1,292)=10.8, \mathrm{p}=0.001$ \\
Negative outcomes & $34.7(0.62)$ & $38.5(0.58)$ & $\mathrm{F}(1,292)=20.83, \mathrm{p}=0.000$ \\
Positive outcomes & Low & High & \\
Negative Coping & $32.4(0.97)$ & $41.5(0.95)$ & $\mathrm{F}(1,292)=52.5, \mathrm{p}=0.000$ \\
Negative Outcomes & Low & High & \\
Positive coping & $35.3(0.59)$ & $37.9(0.55)$ & $\mathrm{F}(1,292)=11.2, \mathrm{p}=0.001$ \\
\hline Positve outcomes & & & \\
\hline
\end{tabular}

Table 3. Means for the interaction established predictors and nationality.

\begin{tabular}{|c|c|c|}
\hline & Mean (SD) & Mean (SD) \\
\hline & \multicolumn{2}{|c|}{ Positive Work Characteristics } \\
\hline & Low & High \\
\hline \multicolumn{3}{|l|}{ Nationality } \\
\hline $\begin{array}{c}\text { White British } \\
\text { (Negative Outcomes) }\end{array}$ & $35.5(1.68)$ & $38.95(1.60)$ \\
\hline $\begin{array}{c}\text { Ethnic Minority } \\
\text { (Negative Outcomes) }\end{array}$ & $34.9(1.42)$ & $36.6(1.50)$ \\
\hline $\begin{array}{c}\text { Nigerian } \\
\text { (Negative Outcomes) }\end{array}$ & $40.97(1.60)$ & $34.9(2.11)$ \\
\hline
\end{tabular}

Furthermore, these findings contribute to the debate on well-being as either being a subjective process or an objective one. While subjectivists believe that well-being is a function of personal attitudes, values and perceptions, the objectivists argue that well-being predictors are universal [25]. As Fonberg and Smith [25] argue, to test for the objectivity or subjectivity of the well-being process in 
an unbiased manner, subjective measures of well-being are required. They suggest that using objective measures imply the availability of no alternatives. This study used the DRIVE model, which places heavy emphasis on the role individual differences play in the well-being process-thus making it a subjective model. Following the logic of Fonberg and Smith [25], the current study seems to further support the argument of well-being as an objective rather than a subjective process. Using the DRIVE model, a subjective model, in this study has shown that nationality/ethnicity plays no role in the well-being process in addition to the fact that the established effects held true.

Although nationality on its own did not predict negative or positive outcomes, its interaction with positive work characteristics predicted negative outcomes. This finding is somewhat in concord with Capasso and colleagues' [22] findings which revealed that Italian factory workers were significantly more likely to experience anxiety and depression when they perceive their work demands as being high. This contrasts with Italian masons who were not significantly likely to experience these symptoms even in high demand situations. Pisanti et al. [23] also reported that, as a result of less favourable healthcare work context, Italian nurses experienced lower positive outcomes and higher negative outcomes than their Dutch counterparts. And although it could be argued that the contexts and perception of the nursing profession in both countries starkly differ, Capasso and colleagues [22] and Pisanti et al. [23] findings seem to suggest that nationality/ethnicity combined with job characteristics predict negative outcomes.

Age seems to play an important role in the prediction of the outcomes and although its interactions with nationality did not yield significant effects in the prediction of both negative and positive outcomes, it significantly predicted both outcomes when established factors were controlled. This could indicate that age is a very important factor in the well-being process and should be studied in more detail in future studies.

As has been previously mentioned, nationality did not significantly predict positive outcomes. Additionally, no significant effects were observed in the two-way interactions between each established predictor and nationality. This seems to suggest that nationality plays no role whatsoever in the well-being process as far as the prediction of positive outcomes is concerned. This contrasts with Pisanti et al [23]'s findings, which showed that despite less favourable job characteristics, Italian nurses experienced higher levels of positive outcomes in comparison to their Dutch colleagues. There are at least two plausible explanations for this variance in findings. The first is that the outcome considered in the Pisanti et al. [23] study was personal accomplishment as opposed to the current study which aggregated happiness, life satisfaction and so on into a composite positive outcome score. Hence, it could imply that nationality differences only applied to positive accomplishment as measured in that study. Secondly, Pisanti et al. [23]'s study considered a homogenous occupational sample as opposed to the cross-sectional occupational sample in this study. 


\section{Conclusion}

Most of the established effects of well-being were observed while nationality alone did not predict any of the outcomes. This seems to suggest that well-being is an objective process which is not influenced by national, ethnic or cultural differences. However, when nationality interacted with one of the established predictors, significant effects were observed. Thus, it can be concluded that although nationality/ethnicity does not automatically predispose an individual to experiencing negative or positive outcomes, when it interacts with other factors like work characteristics it can have a significant impact, particularly in the prediction of negative outcomes.

\section{Acknowledgements}

The authors are grateful to all that participated in the study.

\section{Conflicts of Interest}

The authors declare no conflicts of interest regarding the publication of this paper.

\section{References}

[1] Ryan, R.M. and Deci, E.L. (2001) On Happiness and Human Potentials: A Review of Research on Hedonic and Eudaimonic Well-being. Annual Review of Psychology, 52,141-166. https://doi.org/10.1146/annurev.psych.52.1.141

[2] Caccioppo, J.T. and Bernston G.B. (1999) The Affect System: Architecture and Operating Characteristics. Current Direction in Psychological Science, 8,133-137. https://doi.org/10.1111/1467-8721.00031

[3] Williams, G.M., Pendlebury, H. and Smith, A.P. (2017) Stress and Well-Being of Nurses: An Investigation using the Demands-Resources Individual Effects (DRIVE) Model and Well-Being Process Questionnaire (WPQ). Jacobs Journal of Depression and Anxiety, 1.

[4] Smith, A.P. and Wadsworth, E.A. (2011) A Holistic Approach to Stress and Wellbeing. Part 5: What is a Good Job? Occupational Health (At work), 8, 25-27.

[5] Mark, G. and Smith, A.P. (2008) Stress Models: A Review and Suggested New Direction In: Houdmont, J and Leka, S., Eds., Occupational Health Psychology, Nottingham University Press, Vol. 3, 111-144.

[6] Fan, J.L. and Smith, A.P. (2018) The Mediating Effect of Fatigue on Work-Life Balance and Positive Well-Being in Railway Staff. Open Journal of Social Sciences, 6, 1-10. https://doi.org/10.4236/jss.2018.66001

[7] Smith, A.P. (2018) Cognitive Fatigue and the Wellbeing ant the Attainment of University Students. Journal of Education, Society and Behavioural Science, 24, 1-12. https://doi.org/10.9734/JESBS/2018/39529

[8] Williams, G. and Smith, A.P. (2018) A Longitudinal Study of the Well-Being of Students Using the Student Wellbeing Process Questionnaire (Student WPQ). Journal of Education, Society and Behavioural Science, 24, 1-6. https://doi.org/10.9734/JESBS/2018/40105

[9] Williams, G., Thomas, K. and Smith, A.P. (2017) Stress and Well-Being of Univer- 
sity Staff: An Investigation Using the Demands-Resource-Individual Effects (DRIVE) Model and Well-Being Process Questionnaire (WPQ). Psychology, 8, 1919-1940. https://doi.org/10.4236/psych.2017.812124

[10] Zurlo, M.C., Vallone, F. and Smith, A.P. (2018) Effects of Individual Differences and Job Characteristics on the Psychological Health of Italian Nurses. Europe's Journal of Psychology, 14, 159-175. https://doi.org/10.5964/ejop.v14i1.1478

[11] Williams, G. and Smith, A. (2012) A Holistic Approach to Stress and Wellbeing Part 6: The Wellbeing Process Questionnaire (WPQ). Occupational Health at Work, 9 , 29-31.

[12] Williams, G.M. and Smith, A.P. (2016) Using Single-Item Measures to Examine Relationships between Work, Personality and Well-Being in the Workplace. Psychology, 7, 753-767. https://doi.org/10.4236/psych.2016.76078

[13] Wanous, J.P. and Hudy, M.J. (2001) Single-Item Reliability: A Replication and Extension. Organizational Research Methods, 4, 361-375. https://doi.org/10.1177/109442810144003

[14] Wanous, J.P., Reichers, A.E. and Hudy, M.J. (1997) Overall Job Satisfaction: How Good are Single-Item Measures? Journal of Applied Psychology, 82, 247-252. https://doi.org/10.1177/109442810144003

[15] Williams, G.M. (2014) Researching and Developing Mental Health and Well-Being Assessment Tools for Supporting Employers and Employees in Wales. Ph.D. Thesis, Cardiff University.

[16] Williams, G.M. (2012) Developing Short, Physical Measures of Well-being. In: Anderson, M., Ed., Contemporary Ergonomics and Human Factors, Taylor and Francis, London. https://doi.org/10.1201/b11933-52

[17] Smith, A.P and Smith, H.N. (2017) An International Survey of the Wellbeing of Employees in the Business Process Outsourcing Industry. Psychology, 8, 160-167. https://doi.org/10.4236/psych.2017.81010

[18] Fan, J.L. and Smith, A.P. (2017) Positive Well-Being and Work-Life Balance among UK Railway Staff. Open Journal of Social Sciences, 5, 1-6. https://doi.org/10.4236/jss.2017.56001

[19] Smith, A.P. and Smith, H.N. (2017) Workload, Fatigue and Performance in the Rail Industry. In: Longo, L. and Leva, M., Eds. Human Mental Workload: Models and Applications. H-WORKLOAD 2017. Communications in Computer and Information Science, Vol. 726, Springer, Cham. https://doi.org/10.1007/978-3-319-61061-0_17

[20] Zaiedy Nor, N.I. and Smith, A.P. (2018) Attitudes to Training and Their Relation to the Well-Being of Workers. Journal of Education, Society and Behavioural Science, 27, 1-19. https://doi.org/10.9734/JESBS/2018/44445

[21] Omosehin, O. and Smith, A.P. (2018) Adding New Variables to the Well-Being Process Questionnaire (WPQ) - Further Studies of Workers and Students. Journal of Education, Society and Behavioural Science, 28, 1-19. https://doi.org/10.9734/JESBS/2018/45535

[22] Capasso, R., Zurlo, M.C. and Smith, A. (2016) Work Characteristics and Occupational Health in Different Ethnic Groups. Proceedings at the Ergonomic and Human Factors 2016, Northamptonshire, UK, 19-21 April 2016.

[23] Pisanti, R., van der Doef, M., Maes, S., Lazzari, D. and Bertini, M. (2011) Job Characteristics, Organizational Conditions, and Distress/Well-Being among Italian and Dutch Nurses: A Cross-National Comparison. International Journal of Nursing Stu- 
dies, 48, 829-837. https://doi.org/10.1016/j.ijnurstu.2010.12.006

[24] Lim, J., Bogossian, F. and Ahern, K. (2010) Stress and Coping in Singaporean Nurses: A Literature Review. Nursing and Health Sciences, 12, 251-258. https://doi.org/10.1111/j.1442-2018.2010.00514.x

[25] Fonberg, J. and Smith, A.P. (2019) The Validity of a Single Question about Life Satisfaction. International Journal of Arts, Humanities and Social Sciences, 4, 38-44. 